\title{
Fixed point theorems of generalized multi-valued mappings in cone $b$-metric spaces
}

\author{
Mani Gunaseelan, Lakshmi Narayan Mishra, \\ VISHNU NARAYAN MISHRA*
}

\begin{abstract}
The aim of this paper is to establish fixed points for multivalued mappings, by adapting the ideas in [1] to the cone $b$-metric space setting.
\end{abstract}

\section{INTRODUCTION AND PRELIMINARIES}

The well-known Banach contraction principle and its several generalization in the setting of metric spaces play a central role for solving many problems of nonlinear analysis. For example, see $[3,10,12,20,21]$. Several authors introduced some interesting concept, see [28, 29, 30, 31, 32]. In [4], Bakhtin introduced $b$-metric spaces as a generalization of metric spaces. He proved the contraction mapping principle in $b$-metric spaces that generalized the famous contraction principle in metric spaces. Since then, several papers have dealt with fixed point theory or the variational principle for single-valued and multi-valued operators in $b$-metric spaces(see $[6,7,11]$ and reference therein). In recent investigations, the fixed point in non-convex analysis, especially in an ordered normed space, occupies a prominent place in many aspects (see [14, 15, 18, 22]). The authors define an ordering by using a cone, which naturally induces a partial ordering in Banach spaces. In 2007, Huang and Zhang [14] introduced the concept of cone metric spaces as a generalization of metric spaces and establish some fixed point theorems for contractive mappings in normal cone metric spaces. Subsequently, several other authors $[2,16,23,25]$ studied the existence of fixed points and common fixed points of mappings satisfying contractive type condition on a normal cone metric space. Recently, Rezapour and Hamlbarani [23] omitted the assumption of normality in cone metric space, which is a milestone in developing fixed point theory in cone metric space. In 2011, Hussain and

2020 Mathematics Subject Classification. Primary: 47H10; Secondary: 54H25.

Key words and phrases. Cone $b$-metric space, Multi-valued mappings, Fixed point.

Full paper. Received 1 July 2020, revised 1 September 2020, accepted 1 October 2020, available online 16 March 2021.

${ }^{*}$ Corresponding author 
Shah [15] introduced the concept of cone $b$-metric space as a generalization of $b$-metric space and cone metric spaces. They established some topological properties in such space and improved some recent results about KKM mappings in the setting of a cone $b$-metric space. In 2020, Wasfi Shatanawi, Zoran D. Mitrović, Nawab Hussain and Stojan Radenović [33] proved Generalized Hardy-Rogers Type $\alpha$-Admissible Mappings in Cone $b$-Metric Spaces over Banach Algebras. Krishnakumar and Marudai [1] proved the following fixed point theorems of multi-valued mappings in cone metric spaces.

Theorem 1. Let $(X, d)$ be a complete cone metric space and the mapping $T: X \rightarrow C B(X)$ be multi-valued map satisfying for each $x, y \in X$,

$$
H(T x, T y) \leq a[d(x, T x)+d(y, T y)]+b[d(x, T y)+d(T x, y)]
$$

for all $x, y \in X$, and $a+b<\frac{1}{2}, a, b \in\left[0, \frac{1}{2}\right)$. Then $T$ has a fixed point in $X$.

Theorem 2. Let $(X, d)$ be a complete cone metric space and the mapping $T: X \rightarrow C B(X)$ be multi-valued map satisfy the condition,

$$
H(T x, T y) \leq r \max \{d(x, y), d(x, T x), d(y, T y)\}
$$

for all $x, y \in X$, and $r \in[0,1)$. Then $T$ has a fixed point in $X$.

Theorem 3. Let $(X, d)$ be a complete cone metric space and $P$ a normal cone with normal constant $K$. Suppose the mapping $T: X \rightarrow C B(X)$ be multi valued mapping satisfying the condition

$$
H(T x, T y) \leq r \max \{d(x, y), d(x, T x), d(y, T y), d(x, T y), d(y, T x)\}
$$

for all $x, y \in X$, and $r \in[0,1)$. Then $T$ has a unique fixed point in $X$.

Definition 1 ([14]). Let $E$ be a real Banach space. A subset $P$ of $E$ is called a cone whenever the following conditions hold:

$\left(C_{1}\right) P$ is closed, nonempty and $P \neq\{0\}$;

$\left(C_{2}\right) a, b \in R, a, b \geq 0$ and $x, y \in P$ imply $a x+b y \in P$;

$\left(C_{3}\right) P \cap(-P)=\{0\}$.

Given a cone $P \subset E$, we define a partial ordering $\leq$ with respect to $P$ by $x \leq y$ if and if $y-x \in P$. We shall write $x<y$ to indicate that $x \leq y$ but $x \neq y$, while $x \ll y$ will stand for $y-x \in P^{0}$, where $P^{0}$ stands for the interior of $P$. If $P^{0} \neq \emptyset$ then $P$ is called a solid cone(see[23]).

There exist two kinds of cone-normal(with the normal constant $K$ ) and nonnormal ones [12].

Let $E$ be a real Banach space, $P \subset E$ a cone and $\leq$ partial ordering defined by $P$. Then $P$ is called normal if there is a number $K>0$ such that for all $x, y \in P$,

$$
0 \leq x \leq y \quad \text { imply } \quad\|x\| \leq K\|y\|
$$


or equivalently, if $(\forall n) x_{n} \leq y_{n} \leq z_{n}$ and

$$
\lim _{n \rightarrow \infty} x_{n}=\lim _{n \rightarrow \infty} z_{n}=x \quad \text { imply } \quad \lim _{n \rightarrow \infty} y_{n}=x .
$$

The least positive number $K$ satisfying (1) is called the normal constant of $P$.

The cone $P$ is called regular if every increasing sequence which is bounded above is convergent and every decreasing sequence which is bounded below is convergent.

Example 1 (see [24]). Let $E=C_{\mathbb{R}}^{1}[0,1]$ with $\|x\|=\|x\|_{\infty}+\left\|x^{\prime}\right\|_{\infty}$ on $P=\{x \in E: x(t) \geq 0\}$. This cone is not normal. Consider, for example, $x_{n}(t)=\frac{t^{n}}{n}$ and $y_{n}(t)=\frac{1}{n}$. Then $0 \leq x_{n} \leq y_{n}$, and $\lim _{n \rightarrow \infty} y_{n}=0$, but $\left\|x_{n}\right\|=\max _{t \in[0,1]}\left|\frac{t^{n}}{n}\right|+\max _{t \in[0,1]}\left|t^{n-1}\right|=\frac{1}{n}+1>1$; hence $x_{n}$ does not converge to zero. It follows by (2) that $P$ is a non-normal cone.

Definition 2 ([14, 26]). Let $X$ be a nonempty set. Suppose that the mapping $d: X \times X \rightarrow E$ satisfies:

$\left(\mathrm{d}_{1}\right) 0 \leq d(x, y)$ for all $x, y \in X$ with $x \neq y$ and $d(x, y)=0$ if and only if $x=y$;

$\left(\mathrm{d}_{2}\right) d(x, y)=d(y, x)$ for all $x, y \in X$;

$\left(\mathrm{d}_{3}\right) d(x, y) \leq d(x, z)+d(z, y) x, y, z \in X$.

Then $d$ is called a cone metric [14] or $K$-metric [26] on $X$ and $(X, d)$ is called a cone metric [14] or $K$-metric space [26].

The concept of a cone metric space is more general than that of a metric space, because each metric space is a cone metric space where $E=\mathbb{R}$ and $P=[0,+\infty)$.

Example 2 (see [14]). Let $E=\mathbb{R}^{2}, P=\left\{(x, y) \in \mathbb{R}^{2}: x \geq 0, y \geq 0\right\}$, $X=\mathbb{R}$ and $d: X \times X \rightarrow E$ defined by $d(x, y)=(|x-y|, \alpha|x-y|)$, where $\alpha \geq 0$ is a constant. Then $(X, d)$ is a cone metric space with normal cone $P$ where $K=1$.

Example 3 (see [22]). Let $E=\ell^{2}, P=\left\{\left\{x_{n}\right\}_{n \geq} \in E: x_{n} \geq\right.$ 0foralln $\}$, $(X, \rho)$ a metric space, and $d: X \times X \rightarrow E$ defined by $d(x, y)=\left\{\rho(x, y) / 2^{n}\right\}_{n \geq 1}$. Then $(X, d)$ is a cone metric space.

Clearly, the above examples show that class of cone metric spaces contains the class of metric spaces.

Definition 3 ([15]). Let $X$ be a nonempty set and $s \geq 1$ be a given real number. A mapping $d: X \times X \rightarrow E$ is said to be cone $b$-metric if and only if, for all $x, y, z \in X$, the following conditions are satisfied:

(i) $0 \leq d(x, y)$ with $x \neq y$ and $d(x, y)=0$ if and only if $x=y$;

(ii) $d(x, y)=d(y, x)$;

(iii) $d(x, y) \leq s[d(x, z)+d(z, y)]$.

The pair $(X, d)$ is called a cone $b$-metric space. 
Remark 1. The class of cone $b$-metric spaces is larger than the class of cone metric space since any cone metric spaces must be a cone $b$-metric spaces. Therefore, it is obvious that cone $b$-metric spaces generalize $b$-metric spaces and cone metric spaces.

We give some examples, which show that introducing a cone $b$-metric space instead of a cone metric space is meaningful since there exist cone $b$-metric space which are not cone metric space.

Example 4 (see [13]). Let $E=\mathbb{R}^{2}, P=\{(x, y) \in E: x \geq 0, y \geq 0\} \subset E$, $X=\mathbb{R}$ and $d: X \times X \rightarrow E$ defined by $d(x, y)=\left(|x-y|^{p}, \alpha|x-y|^{p}\right)$, where $\alpha \geq 0$ and $p>1$ are two constants. Then $(X, d)$ is a cone $b$-metric space with the coefficient $s=2^{p}>1$, but not a cone metric space.

Example 5 (see [13]). Let $X=\ell^{p}$ with $0<p<1$, where $\ell^{p}=\left\{\left\{x_{n}\right\} \subset\right.$ $\left.\mathbb{R}: \sum_{n=1}^{\infty}\left|x_{n}\right|^{p}<\infty\right\}$. Let $d: X \times X \rightarrow \mathbb{R}_{+}$defined $d(x, y)=\left(\sum_{n=1}^{\infty}\left|x_{n}-y_{n}\right|^{p}\right)^{\frac{1}{p}}$, where $x=\left\{x_{n}\right\}, y=\left\{y_{n}\right\} \in \ell^{p}$. Then $(X, d)$ is a cone $b$-metric space with the coefficient $s=2^{p}>1$, but not a cone metric space.

Example 6 (see [13]). Let $X=\{1,2,3,4\}, E=\mathbb{R}^{2}, P=\{(x, y) \in E: x \geq$ $0, y \geq 0\}$. Define $d: X \times X \rightarrow E$ by

$$
d(x, y)=\left\{\begin{array}{cl}
\left(|x-y|^{-1},|x-y|^{-1}\right), & \text { if } x \neq y \\
0, & \text { if } x=y .
\end{array}\right.
$$

Then $(X, d)$ is a cone $b$-metric space with the coefficient $s=\frac{6}{5}>1$. But it is not a cone metric space since the triangle inequality is not satisfied,

$$
d(1,2)>d(1,4)+d(4,2), \quad d(3,4)>d(3,1)+d(1,4) .
$$

Definition 4 ([14]). Let $(X, d)$ be a cone $b$-metric space, $x \in X$ and $\left\{x_{n}\right\}$ be a sequence in $X$. Then:

(i) $\left\{x_{n}\right\}$ is a Cauchy sequence whenever, if for every $c \in E$ with $0 \ll$ $c$, then there is natural number $N$ such that for all $n, m \geq N$, $d\left(x_{n}, x_{m}\right) \ll c ;$

(ii) $\left\{x_{n}\right\}$ converges to $x$ whenever, for every $c \in E$ with $0 \ll c$, then there is a natural number $N$ such that for all $n \geq N, d\left(x_{n}, x\right) \ll c$. We denote this by $\lim _{n \rightarrow \infty} x_{n}=x$ or $x_{n} \rightarrow x$ as $n \rightarrow \infty$.

(iii) $(X, d)$ is a complete cone $b$-metric space if every Cauchy sequence is convergent.

In the following $(X, d)$ will stand for a cone $b$-metric space with respect to a cone $P$ with $P^{0} \neq \emptyset$ in a real Banach space $E$ and $\leq$ is partial ordering in $E$ with respect to $P$. The following lemmas are often used(in particular while dealing with cone metric spaces in which the cone need not be normal). 
Lemma 1 ([18]). Let $P$ be a cone and $\left\{a_{n}\right\}$ be a sequence in $E$. If $c \in$ intP and $0 \leq a_{n} \rightarrow 0$ as $n \rightarrow \infty$, then there exists $N$ such that for all $n>N$, we have $a_{n} \ll c$.

Lemma 2 ([18]). Let $x, y, z \in E$, if $x \leq y$ and $y \ll z$, then $x \ll z$.

Lemma 3 ([15]). Let $P$ be a cone and if $0 \leq u \ll c$ for each $c \in$ int $P$, then $u=0$.

Lemma 4 ([9]). Let $P$ be a cone, if $u \in P$ and $u \leq k u$ for some $0 \leq k<1$, then $u=0$.

Lemma 5 ([18]). Let $P$ be a cone and $a \leq b+c$ for each $c \in$ int $P, a \leq b$.

Let $(X, d)$ be a metric space. We denote by $C B(X)$ the family of nonempty closed bounded subset of $X$. Let $H$ be the Hausdorff distance on $C B(X)$. That is, for $A, B \in C B(X)$,

$$
H(A, B)=\max \left\{\sup _{a \in A} d(a, B), \sup _{b \in B} d(A, b)\right\},
$$

where $d(a, B)=\inf \{d(a, b): b \in B\}$ is the distance from the point a to the subset $B$. An element $x \in X$ is said to be a fixed point of a multi-valued mapping $T: X \rightarrow 2^{X}$ if $x \in T(X)$.

In this paper, we study the existence of fixed points for multi-valued mappings by adapting the ideas in [1] to the cone $b$-metric spaces setting.

\section{MAIn RESUlts}

Theorem 4. Let $(X, d)$ be a complete cone b-metric space with the coefficient $s \geq 1$ and the mapping $T: X \rightarrow C B(X)$ be multi-valued map satisfying for each $x, y \in X$

$$
H(T x, T y) \leq a[d(x, T x)+d(y, T y)]+b[d(x, T y)+d(T x, y)]
$$

for all $x, y \in X$, and $a, b \in[0,1)$ are constants such that $2 a+2 b s<1$. Then $T$ has a fixed point in $X$.

Proof. For every $x_{0} \in X$ and $n \geq 1, x_{1} \in T x_{0}$ and $x_{n+1} \in T x_{n}$. We have

$$
\begin{aligned}
d\left(x_{n+1}, x_{n}\right) \leq & H\left(T x_{n}, T x_{n-1}\right) \\
\leq & a\left[d\left(x_{n}, T x_{n}\right)+d\left(x_{n-1}, T x_{n-1}\right)\right] \\
& +b\left[d\left(x_{n}, T x_{n-1}\right)+d\left(T x_{n}, x_{n-1}\right)\right] \\
\leq & a\left[d\left(x_{n}, x_{n+1}\right)+d\left(x_{n-1}, x_{n}\right)\right]+b\left[d\left(x_{n}, x_{n}\right)+d\left(x_{n+1}, x_{n-1}\right)\right] \\
\leq & a\left[d\left(x_{n}, x_{n+1}\right)+d\left(x_{n-1}, x_{n}\right)\right]+b\left[d\left(x_{n+1}, x_{n-1}\right)\right] \\
\leq & a\left[d\left(x_{n}, x_{n+1}\right)+d\left(x_{n-1}, x_{n}\right)\right] \\
& +b s\left[d\left(x_{n+1}, x_{n}\right)+d\left(x_{n}, x_{n-1}\right)\right] \\
\leq & (a+b s)\left[d\left(x_{n}, x_{n+1}\right)+d\left(x_{n-1}, x_{n}\right)\right],
\end{aligned}
$$

$$
d\left(x_{n+1}, x_{n}\right) \leq L d\left(x_{n}, x_{n-1}\right),
$$


where $L=\frac{a+b s}{1-(a+b s)}$. As $2 a+2 b s<1$, we obtain that $L<1$. Similarly, we obtain

$$
d\left(x_{n}, x_{n+1}\right) \leq L d\left(x_{n-1}, x_{n-2}\right) .
$$

Using (5) in (4), we get

$$
d\left(x_{n+1}, x_{n}\right) \leq L^{2} d\left(x_{n}, x_{n-1}\right) .
$$

Continuing this process, we obtain

$$
d\left(x_{n+1}, x_{n}\right) \leq L^{n} d\left(x_{1}, x_{0}\right) .
$$

For any $m \geq 1, p \geq 1$, we have

$$
\begin{aligned}
d\left(x_{m}, x_{m+p}\right) & \leq s\left[d\left(x_{m}, x_{m+1}\right)+d\left(x_{m+1}, x_{m+p}\right)\right] \\
& =s d\left(x_{m}, x_{m+1}\right)+s d\left(x_{m+1}, x_{m+p}\right) \\
& \leq s d\left(x_{m}, x_{m+1}\right)+s^{2}\left[d\left(x_{m+1}, x_{m+2}\right)+d\left(x_{m+2}, x_{m+p}\right)\right] \\
& =s d\left(x_{m}, x_{m+1}\right)+s^{2} d\left(x_{m+1}, x_{m+2}\right)+s^{2} d\left(x_{m+2}, x_{m+p}\right) \\
& \leq s d\left(x_{m}, x_{m+1}\right)+s^{2} d\left(x_{m+1}, x_{m+2}\right)+s^{3} d\left(x_{m+2}, x_{m+3}\right) \\
& +\cdots+s^{p-1} d\left(x_{m+p-2}, x_{m+p-1}\right)+s^{p-1} d\left(x_{m+p-1}, x_{m+p}\right) \\
& \leq s L^{m} d\left(x_{1}, x_{0}\right)+s^{2} L^{m+1} d\left(x_{1}, x_{0}\right)+s^{3} L^{m+2} d\left(x_{1}, x_{0}\right) \\
& +\cdots+s^{p-1} L^{m+p-2} d\left(x_{1}, x_{0}\right)+s^{p} L^{m+p-1} d\left(x_{1}, x_{0}\right) \\
& =s L^{m}\left[1+s L+s^{2} L^{2}+s^{3} L^{3}+\cdots+(s L)^{p-1}\right] d\left(x_{1}, x_{0}\right) \\
& \leq\left(\frac{s L^{m}}{1-s L}\right) d\left(x_{1}, x_{0}\right) .
\end{aligned}
$$

Let $0 \ll r$ be given. Note that $\left(\frac{s L^{m}}{1-s L}\right) d\left(x_{1}, x_{0}\right) \rightarrow 0$ as $m \rightarrow \infty$ for any $p$. Making full use of ([13], Lemma 1.8), we find $m_{0} \in \mathbb{N}$ such that

$$
\left(\frac{s L^{m}}{1-s L}\right) d\left(x_{1}, x_{0}\right) \ll r
$$

for each $m>m_{0}$. Thus,

$$
d\left(x_{m}, x_{m+p}\right) \leq\left(\frac{s L^{m}}{1-s L}\right) d\left(x_{1}, x_{0}\right) \ll r
$$

for all $m \geq 1, p \geq 1$. Therefore, $\left\{x_{n}\right\}$ is a Cauchy sequence in $(X, d)$. Since $(X, d)$ is a complete cone $b$-metric space, there exists $z \in X$ such that $x_{n} \rightarrow z$ as $n \rightarrow \infty$. Take $n_{0} \in \mathbb{N}$ such that $d\left(x_{n}, z\right) \ll r \frac{1-a s-b s}{s(1+b)}$ for all $n>n_{0}$. Hence,

$$
\begin{aligned}
d(z, T z) & \leq s\left[d\left(z, x_{n+1}\right)+d\left(x_{n+1}, T z\right)\right] \\
& \leq s d\left(z, T x_{n}\right)+s H\left(T x_{n}, T z\right) \\
& \leq s d\left(z, x_{n+1}\right)+s\left[a\left(d\left(x_{n}, T x_{n}\right)+d(z, T z)\right)\right. \\
& \left.+b\left(d\left(x_{n}, T z\right)+d\left(T x_{n}, z\right)\right)\right]
\end{aligned}
$$




$$
\begin{aligned}
& \leq s d\left(z, x_{n+1}\right)+s\left[a \left(d\left(x_{n}, x_{n+1}\right)\right.\right. \\
& \left.+d(z, T(z)))+b\left(d\left(x_{n}, T z\right)+d\left(x_{n+1}, z\right)\right)\right] .
\end{aligned}
$$

This implies that

$$
d(z, T z) \leq\left(\frac{s(1+b)}{1-a s-b s}\right) d\left(x_{n}, z\right) \ll r,
$$

for $n>n_{0}$. Then, by Lemma (1.10), we deduce that $d(T z, z)=0$, that is $T z=z$.

Example 7. Let $X=[0,1]$ endowed with the standard order and $E=$ $C_{R}^{1}[0,1]$ with $\|u\|=\|u\|_{\infty}+\left\|u^{\prime}\right\|_{\infty}, u \in E$ and let $P=\{u \in E: u(t) \geq$ 0 on $[0,1]\}$. It is well known that this cone is solid, but it is not normal. Define a cone $b$-metric $d: X \times X \rightarrow E$ by $d(x, y)(t)=|x-y|^{2} \exp ^{t}$. Then $(X, d)$ is a complete cone $b$-metric space with the coefficient $s=2$. Define $T: X \rightarrow C B(X)$ by

$$
T(x)=\left\{\begin{array}{lll}
\left\{\frac{1}{3}, \frac{2}{3}\right\}, & \text { if } \quad 0 \leq x<1 \\
\left\{\frac{1}{3}\right\}, & \text { if } \quad x=1
\end{array}\right.
$$

Let $x, y \in X$. Without loss of generality, take $x \leq y$.

If $x=y$ or $x, y<1$, then $T x=T y$. Hence $H(T x, T y)=0$.

If $x<1$ and $y=1$, then

$$
\begin{aligned}
H(T x, T y) & =\frac{1}{9} \exp ^{t} \\
& \leq \frac{4}{27} \exp ^{t} \\
& =\frac{1}{3} \cdot \frac{4}{9} \exp ^{t} \\
& =\frac{1}{3}(d(x, T x)+d(y, T y)) \\
& \leq b(d(x, T x)+d(y, T y))
\end{aligned}
$$

where $b=\frac{1}{3} \in[0,1)$ and $a=0$. So all the conditions of Theorem 2.1 are satisfied. Moreover, $\frac{1}{3}$ and $\frac{2}{3}$ are the two fixed points of $T$.

Corollary 1. Let $(X, d)$ be a complete cone b-metric space with the coeffcient $s \geq 1$ and the mapping $T: X \rightarrow C B(X)$ be multi valued map satisfies condition

$$
d(T x, T y) \leq b(d(x, T y)+d(x, T y))
$$

for all $x, y \in X$, where $b \in\left[0, \frac{1}{2 s}\right)$ is a constant. Then $T$ has a fixed point in $X$.

Proof. The proof of the corollary immediately follows by putting $a=0$ in the previous theorem. 
Corollary 2. Let $(X, d)$ be a complete cone b-metric space with the coefficient $s \geq 1$ and the mapping $T: X \rightarrow C B(X)$ be multi valued map satisfies condition

$$
d(T x, T y) \leq a(d(x, T x)+d(y, T y))
$$

for all $x, y \in X$, where $a \in\left[0, \frac{1}{2 s}\right)$ is a constant. Then $T$ has a fixed point in $X$.

Proof. The proof of the corollary immediately follows by putting $b=0$ in the previous theorem.

Theorem 5. Let $(X, d)$ be a complete cone b-metric space with the coefficient $s \geq 1$ and the mapping $T: X \rightarrow C B(X)$ be multi valued map satisfy the condition, $H(T x, T y) \leq r \max \{d(x, y), d(x, T x), d(y, T y)\}$ for all $x, y \in X$, and $r \in[0,1)$. Then $T$ has a unique fixed point in $X$.

Proof. For every $x_{0} \in X$ and $n \geq 1, x_{1} \in T x_{0}$ and $x_{n+1} \in T x_{n}$

$$
\begin{aligned}
d\left(x_{n+1}, x_{n}\right) & \leq H\left(T x_{n}, T x_{n-1}\right) \\
& \leq r \max \left\{d\left(x_{n}, x_{n-1}\right), d\left(x_{n}, T x_{n}\right), d\left(x_{n-1}, T x_{n-1}\right)\right\} \\
& \leq r \max \left\{d\left(x_{n}, x_{n-1}\right), d\left(x_{n}, x_{n+1}\right), d\left(x_{n-1}, x_{n}\right)\right\} \\
& \leq r d\left(x_{n-1}, x_{n}\right) \\
& \leq r^{n} d\left(x_{1}, x_{0}\right)
\end{aligned}
$$

For any $m \geq 1, p \geq 1$, we have

$$
\begin{aligned}
d\left(x_{m}, x_{m+p}\right) & \leq s\left[d\left(x_{m}, x_{m+1}\right)+d\left(x_{m+1}, x_{m+p}\right)\right] \\
& =s d\left(x_{m}, x_{m+1}\right)+s d\left(x_{m+1}, x_{m+p}\right) \\
& \leq s d\left(x_{m}, x_{m+1}\right)+s^{2}\left[d\left(x_{m+1}, x_{m+2}\right)+d\left(x_{m+2}, x_{m+p}\right)\right] \\
& =s d\left(x_{m}, x_{m+1}\right)+s^{2} d\left(x_{m+1}, x_{m+2}\right)+s^{2} d\left(x_{m+2}, x_{m+p}\right) \\
& \leq s d\left(x_{m}, x_{m+1}\right)+s^{2} d\left(x_{m+1}, x_{m+2}\right)+s^{3} d\left(x_{m+2}, x_{m+3}\right) \\
& +\cdots+s^{p-1} d\left(x_{m+p-2}, x_{m+p-1}\right)+s^{p-1} d\left(x_{m+p-1}, x_{m+p}\right) \\
& \leq s r^{m} d\left(x_{1}, x_{0}\right)+s^{2} r^{m+1} d\left(x_{1}, x_{0}\right)+s^{3} r^{m+2} d\left(x_{1}, x_{0}\right) \\
& +\cdots+s^{p-1} r^{m+p-2} d\left(x_{1}, x_{0}\right)+s^{p} r^{m+p-1} d\left(x_{1}, x_{0}\right) \\
& =s r^{m}\left[1+s r+s^{2} r^{2}+s^{3} r^{3}+\cdots+(s r)^{p-1}\right] d\left(x_{1}, x_{0}\right) \\
& \leq\left(\frac{s r^{m}}{1-s r}\right) d\left(x_{1}, x_{0}\right) .
\end{aligned}
$$

Let $0 \ll r$ be given. Note that $\left(\frac{s r^{m}}{1-s r}\right) d\left(x_{1}, x_{0}\right) \rightarrow 0$ as $m \rightarrow \infty$ for any $p$. Making full use of ([13], Lemma 1.8), we find $m_{0} \in \mathbb{N}$ such that

$$
\left(\frac{s r^{m}}{1-s r}\right) d\left(x_{1}, x_{0}\right) \ll c
$$


for each $m>m_{0}$. Thus,

$$
d\left(x_{m}, x_{m+p}\right) \leq\left(\frac{s r^{m}}{1-s r}\right) d\left(x_{1}, x_{0}\right) \ll c
$$

for all $m \geq 1, p \geq 1$. Therefore, $\left\{x_{n}\right\}$ is a Cauchy sequence in $(X, d)$. Since $(X, d)$ is a complete cone $b$-metric space, there exists $z \in X$ such that $x_{n} \rightarrow z$ as $n \rightarrow \infty$. Take $n_{0} \in \mathbb{N}$ such that $d\left(x_{n}, z\right) \ll c \frac{1-s}{s}$ for all $n>n_{0}$. Hence,

$$
\begin{aligned}
d(z, T z) & \leq s\left[d\left(z, x_{n+1}\right)+d\left(x_{n+1}, T z\right)\right] \\
& \leq s d\left(z, T x_{n}\right)+s H\left(T x_{n}, T z\right) \\
& \leq s d\left(z, x_{n+1}\right)+s\left[\max \left\{d\left(x_{n}, z\right), d\left(x_{n}, T x_{n}\right), d(z, T z)\right\}\right] \\
& \leq s d\left(z, x_{n+1}\right)+s\left[\max \left\{0, d\left(x_{n}, x_{n+1}\right), d(z, T z)\right\}\right] \\
& \leq s d\left(z, x_{n+1}\right)+s[\max \{0,0, d(z, T z)\}] \\
& \leq s d\left(z, x_{n}\right)+s d(z, T z) .
\end{aligned}
$$

This implies that

$$
d(z, T z) \leq\left(\frac{s}{1-s}\right) d\left(x_{n}, z\right) \ll c,
$$

for $n>n_{0}$. Then, by Lemma (1.10), we deduce that $d(T z, z)=0$, that is $T z=z$.

Assume that there is another fixed point $q$ in $X$ such that $T q=q$.

$$
\begin{aligned}
\therefore d(z, q) & \leq H(T z, T q) \\
& \leq r \max \{d(z, q), d(z, T z), d(q, T q), d(z, T q), d(q, T z)\} \\
& \leq r \max \{d(z, q), d(z, z), d(q, q), d(z, q), d(q, z)\} \\
& \leq r d(z, q)
\end{aligned}
$$

This is contradiction and hence $T$ has a unique fixed point in $X$.

Example 8. Let $X=[0, \infty)$ endowed with the standard order and $E=$ $C_{R}^{1}[0,1]$ with $\|u\|=\|u\|_{\infty}+\left\|u^{\prime}\right\|_{\infty}, u \in E$ and let $P=\{u \in E: u(t) \geq$ 0on $[0,1]\}$. It is well known that this cone is solid, but it is not normal. Define a cone metric $d: X \times X \rightarrow E$ by $d(x, y)(t)=|x-y|^{2} \exp ^{t}$. Then $(X, d)$ is a complete cone $b$-metric space with the coefficient $s=2$. Define $T: X \rightarrow C B(X)$ by

$$
T(x)=\left\{\begin{array}{lll}
\left\{\frac{2}{3}\right\}, & \text { if } & 0 \leq x<1 \\
\left\{\frac{1}{3}\right\}, & \text { if } & x>1
\end{array}\right.
$$

Let $x, y \in X$. Without loss of generality, take $x \leq y$.

If $x=y$ or $x, y<1$, then $T x=T y$. Hence $H(T x, T y)=0$.

If $x<1$ and $y=1$, then 


$$
\begin{aligned}
H(T x, T y) & =\frac{1}{9} \exp ^{t} \\
& \leq \frac{4}{27} \exp ^{t} \\
& =\frac{1}{3} \cdot \frac{4}{9} \exp ^{t} \\
& =\frac{1}{3} d(y, T y) \\
& \leq r \max \{d(x, y), d(x, T x), d(y, T y)\}
\end{aligned}
$$

where $r=\frac{1}{3} \in[0,1)$. So all the conditions of Theorem 2.5 are satisfied. Moreover, 0 is a unique fixed point of $T$.

Corollary 3. Let $(X, d)$ be a complete cone b-metric space with the coefficient $s \geq 1$ and the mapping $T: X \rightarrow C B(X)$ be multi valued mapping satisfy the condition

$$
H(T x, T y) \leq k d(x, y)
$$

for all $x, y \in X$ where $k \in\left[0, \frac{1}{2 s}\right)$ is a constant. Then $T$ has a unique fixed point in $X$.

Proof. The proof of the corollary immediately follows by taking $d(x, y)$ as maximum value in the previous theorem.

We prove the above theorems in the setting of $P$ is a normal cone with normal constant $K$.

Theorem 6. Let $(X, d)$ be a complete cone b-metric space with the coefficient $s \geq 1$ and $P$ a normal cone with normal constant $K$. Suppose the mapping $T: X \rightarrow C B(X)$ be multi valued mapping satisfying the condition, $H(T x, T y) \leq r \max \{d(x, y), d(x, T x), d(y, T y), d(x, T y), d(y, T x)\}$ for all $x, y \in X$, and $r \in[0,1), 2 s r<1$. Then $T$ has a unique fixed point in $X$.

Proof. For every $x_{0} \in X$ and $n \geq 1, x_{1} \in T x_{0}$ and $x_{n+1} \in T x_{n}$,

$$
\begin{aligned}
d\left(x_{n+1}, x_{n}\right) \leq & H\left(T x_{n}, T x_{n-1}\right) \\
\leq & r \max \left\{d\left(x_{n}, x_{n-1}\right), d\left(x_{n}, T x_{n}\right), d\left(x_{n-1}, T x_{n-1}\right),\right. \\
& \left.\quad d\left(x_{n}, T x_{n-1}\right), d\left(x_{n-1}, T x_{n}\right)\right\} \\
\leq & r \max \left\{d\left(x_{n}, x_{n-1}\right), d\left(x_{n}, x_{n+1}\right), d\left(x_{n-1}, x_{n}\right), d\left(x_{n}, x_{n}\right),\right. \\
& \left.\quad d\left(x_{n+1}, x_{n-1}\right)\right\} \\
\leq & r \max \left\{d\left(x_{n-1}, x_{n}\right), d\left(x_{n}, x_{n+1}\right), d\left(x_{n+1}, x_{n-1}\right)\right\} .
\end{aligned}
$$

Case (i)

If $d\left(x_{n+1}, x_{n}\right) \leq r d\left(x_{n}, x_{n-1}\right)$ then we get, $d\left(x_{n+1}, x_{n}\right) \leq r^{n} d\left(x_{1}, x_{0}\right)$.

For any $m \geq 1, p \geq 1$, we have 


$$
\begin{aligned}
d\left(x_{m}, x_{m+p}\right) \leq & s\left[d\left(x_{m}, x_{m+1}\right)+d\left(x_{m+1}, x_{m+p}\right)\right] \\
= & s d\left(x_{m}, x_{m+1}\right)+s d\left(x_{m+1}, x_{m+p}\right) \\
\leq & s d\left(x_{m}, x_{m+1}\right)+s^{2}\left[d\left(x_{m+1}, x_{m+2}\right)+d\left(x_{m+2}, x_{m+p}\right)\right] \\
= & s d\left(x_{m}, x_{m+1}\right)+s^{2} d\left(x_{m+1}, x_{m+2}\right)+s^{2} d\left(x_{m+2}, x_{m+p}\right) \\
\leq & s d\left(x_{m}, x_{m+1}\right)+s^{2} d\left(x_{m+1}, x_{m+2}\right)+s^{3} d\left(x_{m+2}, x_{m+3}\right) \\
& +\cdots+s^{p-1} d\left(x_{m+p-2}, x_{m+p-1}\right)+s^{p-1} d\left(x_{m+p-1}, x_{m+p}\right) \\
\leq & s r^{m} d\left(x_{1}, x_{0}\right)+s^{2} r^{m+1} d\left(x_{1}, x_{0}\right)+s^{3} r^{m+2} d\left(x_{1}, x_{0}\right) \\
& +\cdots+s^{p-1} r^{m+p-2} d\left(x_{1}, x_{0}\right)+s^{p} r^{m+p-1} d\left(x_{1}, x_{0}\right) \\
= & s r^{m}\left[1+s r+s^{2} r^{2}+s^{3} r^{3}+\cdots+(s r)^{p-1}\right] d\left(x_{1}, x_{0}\right) \\
\leq & \left(\frac{s r^{m}}{1-s r}\right) d\left(x_{1}, x_{0}\right) .
\end{aligned}
$$

We get $\left\|d\left(x_{m}, x_{m}+p\right)\right\| \leq K\left(\frac{s r^{m}}{1-s r}\right)\left\|d\left(x_{1}, x_{0}\right)\right\| \cdot d\left(x_{m}, x_{m}+p\right) \rightarrow 0$ as $p, m \rightarrow$ $\infty$. Hence $\left\{x_{m}\right\}$ is a Cauchy sequence. By the completeness of $X$, there is $z \in X$ such that $x_{m} \rightarrow z$ as $m \rightarrow \infty$.

$$
\begin{aligned}
d(z, T z) \leq & s\left[d\left(z, x_{n+1}\right)+d\left(x_{n+1}, T z\right)\right] \\
\leq & s d\left(z, T x_{n}\right)+s H\left(T x_{n}, T z\right) \\
\leq & s d\left(z, x_{n+1}\right)+s\left[r \operatorname { m a x } \left\{d\left(x_{n}, z\right), d\left(x_{n}, T x_{n}\right),\right.\right. \\
& \left.\left.\quad d(z, T z), d\left(x_{n}, T z\right), d\left(z, T x_{n}\right)\right\}\right] \\
\leq & s d\left(z, x_{n+1}\right)+s\left[r \operatorname { m a x } \left\{0, d\left(x_{n}, x_{n+1}\right), d(z, T z),\right.\right. \\
& \left.\left.\quad d\left(x_{n}, T z\right), d\left(z, x_{n+1}\right)\right\}\right] \\
\leq & s d\left(z, x_{n+1}\right)+s[r \max \{0,0, d(z, T z)\}] \\
\leq & s d\left(z, x_{n}\right)+\operatorname{srd}(z, T z) \\
\leq & \operatorname{srd}(z, T z),
\end{aligned}
$$

which implies that $d(T z, z)=0$. Hence $z \in T z$.

\section{Case (ii)}

If $d\left(x_{n+1}, x_{n}\right) \leq r d\left(x_{n+1}, x_{n-1}\right)$ then we get

$$
\begin{aligned}
d\left(x_{n+1}, x_{n}\right) & \leq r s\left[d\left(x_{n+1}, x_{n}\right)+d\left(x_{n}, x_{n-1}\right)\right] \\
& \leq \frac{s r}{1-s r} d\left(x_{n}, x_{n-1}\right) \\
& \leq h d\left(x_{n}, x_{n-1}\right), \quad \text { where } \quad h=\frac{s r}{1-s r}<1 .
\end{aligned}
$$

For any $m \geq 1, p \geq 1$, we have

$$
\begin{aligned}
d\left(x_{m}, x_{m+p}\right) & \leq s\left[d\left(x_{m}, x_{m+1}\right)+d\left(x_{m+1}, x_{m+p}\right)\right] \\
& =s d\left(x_{m}, x_{m+1}\right)+s d\left(x_{m+1}, x_{m+p}\right) \\
& \leq s d\left(x_{m}, x_{m+1}\right)+s^{2}\left[d\left(x_{m+1}, x_{m+2}\right)+d\left(x_{m+2}, x_{m+p}\right)\right]
\end{aligned}
$$




$$
\begin{aligned}
= & s d\left(x_{m}, x_{m+1}\right)+s^{2} d\left(x_{m+1}, x_{m+2}\right)+s^{2} d\left(x_{m+2}, x_{m+p}\right) \\
\leq & s d\left(x_{m}, x_{m+1}\right)+s^{2} d\left(x_{m+1}, x_{m+2}\right)+s^{3} d\left(x_{m+2}, x_{m+3}\right) \\
& +\cdots+s^{p-1} d\left(x_{m+p-2}, x_{m+p-1}\right)+s^{p-1} d\left(x_{m+p-1}, x_{m+p}\right) \\
\leq & s h^{m} d\left(x_{1}, x_{0}\right)+s^{2} h^{m+1} d\left(x_{1}, x_{0}\right)+s^{3} h^{m+2} d\left(x_{1}, x_{0}\right) \\
& +\cdots+s^{p-1} h^{m+p-2} d\left(x_{1}, x_{0}\right)+s^{p} h^{m+p-1} d\left(x_{1}, x_{0}\right) \\
= & s h^{m}\left[1+s h+s^{2} h^{2}+s^{3} h^{3}+\cdots+(s h)^{p-1}\right] d\left(x_{1}, x_{0}\right) \\
\leq & \left(\frac{s h^{m}}{1-s h}\right) d\left(x_{1}, x_{0}\right) .
\end{aligned}
$$

We get $\left\|d\left(x_{m}, x_{m}+p\right)\right\| \leq K\left(\frac{s h^{m}}{1-s h}\right)\left\|d\left(x_{1}, x_{0}\right)\right\| . \quad d\left(x_{m}, x_{m}+p\right) \rightarrow 0$ as $p, m \rightarrow \infty$. Hence $\left\{x_{m}\right\}$ is a Cauchy sequence. By the completeness of $X$, there is $z \in X$ such that $x_{m} \rightarrow z$ as $m \rightarrow \infty$.

$$
\begin{aligned}
d(z, T z) \leq & s\left[d\left(z, x_{n+1}\right)+d\left(x_{n+1}, T z\right)\right] \\
\leq & s d\left(z, T x_{n}\right)+s H\left(T x_{n}, T z\right) \\
\leq & s d\left(z, x_{n+1}\right)+s\left[r \operatorname { m a x } \left\{d\left(x_{n}, z\right), d\left(x_{n}, T x_{n}\right), d(z, T z),\right.\right. \\
& \left.\left.\quad d\left(x_{n}, T z\right), d\left(z, T x_{n}\right)\right\}\right] \\
\leq & s d\left(z, x_{n+1}\right)+s\left[r \operatorname { m a x } \left\{0, d\left(x_{n}, x_{n+1}\right), d(z, T z), d\left(x_{n}, T z\right),\right.\right. \\
& \left.\left.\quad d\left(z, x_{n+1}\right)\right\}\right] \\
\leq & s d\left(z, x_{n+1}\right)+s[r \max \{0,0, d(z, T z)\}] \\
\leq & s d\left(z, x_{n}\right)+\operatorname{srd}(z, T z) \\
\leq & \operatorname{srd}(z, T z) \\
d(T z, z) & 0 .
\end{aligned}
$$

Hence $z \in T z$.

Assume that there is another fixed point $q$ in $X$ such that $T q=q$.

$$
\begin{aligned}
\therefore d(z, q) & \leq H(T z, T q) \\
& \leq r \max \{d(z, q), d(z, T z), d(q, T q), d(z, T q), d(q, T z)\} \\
& \leq r \max \{d(z, q), d(z, z), d(q, q), d(z, q), d(q, z)\} \\
& \leq r d(z, q)
\end{aligned}
$$

This is contradiction and hence $T$ has a unique fixed point in $X$.

Example 9. Let $X=[0,1], E=\mathbb{R}^{2}$. Take $P=\{(x, y) \in E: x, y \geq 0\}$. We define $d: X \times X \rightarrow E$ as $d(x, y)=\left(|x-y|^{2},|x-y|^{2}\right)$ for all $x, y \in X$.

Then $(X, d)$ is a complete cone $b$-metric. Let us define $T: X \rightarrow C B(X)$ as

$$
T(x)=\left\{\begin{array}{lll}
\left\{\frac{2}{5}\right\}, & \text { if } & 0 \leq x<1 \\
\left\{\frac{1}{5}\right\}, & \text { if } & x=1
\end{array}\right.
$$

Let $x, y \in X$. Without loss of generality, take $x \leq y$. 
If $x=y$ or $x, y<1$, then $T x=T y$. Hence $H(T x, T y)=0$.

If $x<1$ and $y=1$, then

$$
\begin{aligned}
H(T x, T y) & =\left(\frac{1}{25}, \frac{1}{25}\right) \leq\left(\frac{16}{125}, \frac{16}{125}\right)=\frac{1}{5}\left(\frac{1}{25}, \frac{1}{25}\right)=\frac{1}{5} d(y, T y) \\
& \leq r \max \{d(x, y), d(x, T x), d(y, T y), d(x, T y), d(y, T x)\},
\end{aligned}
$$

where $r=\frac{1}{5} \in[0,1)$. So all the conditions of Theorem 2.8 are satisfied. Moreover, $\frac{2}{5}$ is a unique fixed point of $T$.

Corollary 4. Let $(X, d)$ be a complete cone b-metric space with the coefficient $s \geq 1$ and $P$ a normal cone with normal constant $K$. Suppose the mapping $T: X \rightarrow C B(X)$ be multi-valued mapping satisfies the condition, $H(T x, T y) \leq r \max \{d(x, y), d(x, T x), d(y, T y)\}$ for all $x, y \in X$, and $r \in[0,1)$. Then $T$ has a unique fixed point in $X$.

Proof. The proof of the corollary immediately follows since

$$
\begin{aligned}
& \max \{d(x, y), d(x, T x), d(y, T y)\} \leq \\
& \max \{d(x, y), d(x, T x), d(y, T y), d(x, T y), d(y, T x)\} .
\end{aligned}
$$

\section{REFERENCES}

[1] R. Krishnakumar and M. Marudai, Fixed point theorems of multivalued mappings in cone metric spaces, International Journal of Contemporary Mathematical Sciences, 5 (31) (2010), 1533-1540.

[2] M. Abbas and G. Jungck, Common fixed point results for non commuting mappings without continuity in cone metric spaces, Journal of Mathematical Analysis and Applications, 341 (2008), 416-420.

[3] R.P. Agarwal, D. O'Regan and R. Precup, Domain invariance theorems for contractive type maps, Dynamic Systems and Applications, 16 (3) (2007), 579-586.

[4] S. Banach, Surles operation dans les ensembles abstraits et leur application aux equation integrals, Fundamenta Mathematica, 3 (1922), 133-181.

[5] I.A. Bakhtin, The contraction mapping principle in quasimetric spaces, Functional Analysis (Unianowsk Gos. Ped. Inst.), 30 (1989), 26-37. (Russian)

[6] M. Boriceanu, M. Bota and A. Petrusel, A multivalued fractals in b-metric spaces, Central European Journal of Mathematics, 8 (2) (2010), 367-377.

[7] M. Bota, A. Moinar and V. Csaba, On Ekeland's variational principle in b-metric spaces, Fixed Point Theory, 12 (2011), 21-28.

[8] S.K. Chatterjae, Fixed point theorems compactes, Comptes Rendus de l'Academie Bulgare des Sciences, 25 (1972), 727-730.

[9] S-H Cho and J-S Bae, Common fixed point theorems for mappings satisfying property(E.A) on cone metric space, Mathematical and Computer Modelling, 53 (2011), 945-951.

[10] L.B. Ćirić, Generalized contractions and fixed point theorems, Publications de l'Institut Mathematique (Nouvelle Serie), 12 (26) (1971), 19-26. 
[11] S. Czerwik, Nonlinear set-valued contraction mappings in b-metric, Atti del Seminario Matematico e Fisico dell'Universitá di Modena, 46 (1998), 263-276.

[12] K. Deimling, Nonlinear Functional Analysis, Springer, Berlin, Germany, 1985.

[13] H. Huang and S. Xu, Fixed point theorems of contractive mappings in cone b-metric spaces and applications, Fixed Point Theory and Applications, 2013 (2013), Article ID: 112,10 pages.

[14] L-G. Huang and X. Zhang, Cone metric spaces and fixed point theorems of contractive mappings, Journal of Mathematical Analysis and Applications, 332 (2) (2007), 14681476 .

[15] N. Hussain and MH. Shah, KKM mappings in cone b-metric spaces, Computers \& Mathematics with Applications, 62 (2011), 1677-1684.

[16] D. Ilic and V. Rakočević, Common fixed points for maps on cone metric space, Journal of Mathematical Analysis and Applications, 341 (2008), 876-882.

[17] D. Ilic and V. Rakočević, Quasi-contraction on a cone metric space, Applied Mathematics Letters, 22 (5) (2009), 728-731.

[18] S. Janković, Z. Kadelburg and S. Radenović, On cone metric spaces: a survey, Nonlinear Analysis, 4 (7) (2011), 2591-2601.

[19] R. Kannan, Some results on fixed point theorems, Bulletin of the Calcutta Mathematical Society, 60 (1969), 71-78.

[20] G. Petruşel and A. Petruşel, Multivalued contractions of Feng-Liu type in complete gauge spaces, Carpthian Journal of Mathematics, 24 (3) (2008), 392-396.

[21] A. Petrusel, Generalized multivalued contractions, Nonlinear Analysis (TMA), 47 (1) (2001), 649-659.

[22] Sh. Rezapour, A review on topological properties of cone metric spaces, in Proceedings of the International Conference on Analysis, Topology and Applications (ATA 08), Vrinjačka Banja, Serbia, May-June 2008.

[23] Sh. Rezapour and R. Hamlbarani, Some notes on the paper cone metric spaces and fixed point theorems of contractive mappings, Journal of Mathematical Analysis and Applications, 345 (2) (2008), 719-724.

[24] J. Vandergraft, Newton method for convex operators in partially ordered spaces, SIAM Journal on Numerical Analysis, 4 (1967), 406-432.

[25] P. Vetro, Common fixed points in cone metric spaces, Rendiconti del Circolo Matematico di Palermo Series 2, 56 (3) (2007), 464-468.

[26] P.P. Zabrejko, K-metric and K-normal linear spaces: survey, Collectanea Mathematica, 48 (4-6) (1997), 825-859.

[27] G. S Saluja, Some fixed point theorems of contractive type conditions in cone b-metric spaces, Nonlinear Analysis Forum, 20 (8) (2015), 241-255.

[28] R. Dubey, Deepmala, V.N. Mishra, Higher-order symmetric duality in nondifferentiable multiobjective fractional programming problem over cone constraints, Statistics, Optimization \& Information Computing, 8 (2020), 187-205. 
[29] L.N. Mishra, V. Dewangan, V.N. Mishra, S. Karateke, Best proximity points of admissible almost generalized weakly contractive mappings with rational expressions on $b$ metric spaces, Journal of Mathematics and Computer Science, 22 (2) (2021), 97-109.

[30] L.N. Mishra, S.K. Tiwari, V.N. Mishra, I.A. Khan, Unique fixed point theorems for generalized contractive mappings in partial metric spaces, Journal of Function Spaces, 2015 (2015), Article ID: 960827, 8 pages.

[31] L. N. Mishra, S.K. Tiwari, V.N. Mishra, Fixed point theorems for generalized weakly $S$-contractive mappings in partial metric spaces, Journal of Applied Analysis and Computation, 5 (4) (2015), 600-612.

[32] X. Liu, M. Zhou, L.N. Mishra, V.N. Mishra, B. Damjanović, Common fixed point theorem of six self-mappings in Menger spaces using $\left(C L R_{S T}\right)$ property, Open Mathematics, 16 (2018), 1423-1434.

[33] Wasfi Shatanawi, Zoran D. Mitrović, Nawab Hussain and Stojan Radenović, On generalized Hardy-Rogers type $\alpha$-admissible mappings in cone b-metric spaces over banach algebras, Symmetry, 12 (1) (2020), Article ID: 81, 12 pages.

\section{Mani Gunaseelan}

Department of Mathematics,

Sri Sankara Arts and Science College(Autonomous)

Affiliated to Madras University

Enathur, Kanchipuram, TAmil Nadu

INDIA 631561

E-mail address: mathsguna@yahoo.com

\section{LAKShMi Narayan Mishra}

Department of Mathematics

School of Advanced Sciences

Vellore Institute of Technology (VIT) University

Vellore 632 014, TAmil Nadu

INDIA

E-mail address: lakshminarayanmishra04@gmail.com

\section{Vishnu Narayan Mishra}

Department of Mathematics

Indira Gandhi National Tribal University

Laipur, Amarkantak, Anuppur

Madhya Pradesh

INDIA 484887

E-mail address: vishnunarayanmishra@gmail.com 